Selma Emre, Gülşen Akoğlu, Sibel Orhun Yavuz*, Gözde Kurtoğlu, Ahmet Metin

\section{Yüzün Multipl Milier Osteoma Kutisi: Bir Olgu}

Miliary Osteoma Cutis of the Face: A Case

\section{Özeł}

Osteoma kutis (kutanöz ossifikasyon) (OK), deri içinde gerçek kemik oluşumlarının görüldüğü nadir bir durumdur. Edinsel bir OK nedeni olan yüzün multipl miliar osteoma kutis (YMMOK)'i, yüz derisi içinde multipl, küçük, primer osteomaların varlığı ile karakterize iyi huylu iskelet dışı nadir kemik formasyonudur. Literatürde bugüne kadar bildirilmiş 52 YMMOK olgusu bulunmaktadır. Elli altı yaşında kadın hasta, alında ve yüzde dört yıldan beri devam eden çok sayıdaki küçük, sert, deri renginde kabarıklıklar şikayeti ile polikliniğimize başvurdu. Lezyon yerlerinde daha önceden geçirilmiş akne veya başka bir inflamatuar hastalık öyküsü olmayan hastadan alınan cilt biyopsisinde, dermiste, santralinde dejenerasyon ve kalsifikasyon bulunan osteoid formasyonu görüldü. Bu klinik ve histopatolojik bulgular ışığında hastaya YMMOK tanısı konuldu.

Anahtar kelimeler: Kutanöz ossifikasyon, osteoma kutis, yüzün milier osteoması

\section{Abstract}

Osteoma cutis (cutaneous ossification) (OC) is a rare disorder with true bone formation within the skin. Multiple miliary osteoma cutis of the face (MMOCF) is a cause of acquired $\mathrm{OC}$, is characterized by multiple, small, and primary osteomas in the skin tissue of the face and is a benign extraskeletal and rare bone formation. To date, 52 cases with MMOCF have been reported in the literature. Herein, we report a 56-year-old female patient presented with multiple small, firm, skin-colored papules on the forehead and face lasting for 4 years. She had no history of preexisting acne or any local inflammatory disease at the lesional sites. The skin biopsy revealed osteoid formation with central degeneration and calcification in the dermis. Depending on these clinical and histopathological findings, the patient was diagnosed as MMOCF.

Key words: Cutaneous ossification, osteoma cutis, miliary osteoma of face

*Atatürk Eğitim ve Araştırma Hastanesi, Patoloji Kliniği, Ankara, Türkiye

\section{Yazışma Adresi/ \\ Correspondence: \\ Selma Emre, Atatürk Eğitim ve Araştırma Hastanesi, Dermatoloji Kliniği, Ankara, Türkiye Tel: +903123341676 E-posta: dr_semre@yahoo.com Geliş Tarihi/Submitted: 31.01.2013 Kabul Tarihi/Accepted: 10.03.2013}

@Telif Hakkı 2014 Türk Dermatoloji Derneği Makale metnine www. turkdermatolojidergisi.com web sayfasından ulaşılabilir.

\section{Giriş}

Osteoma kutis (OK) (kutanöz ossifikasyon), deri içinde gerçek kemik oluşumlarının görüldüğü nadir bir durumdur. Primer olabileceği gibi, inflamatuar olaylar, skarlar, deri tümörleri ve blue nevüslere sekonder olarak da ortaya çıkabilirler. Primer OK herhangi bir predispozan sebep olmadan ortaya çıkan osteomaları tanımlar ve genetik ya da kazanılmış olabilir $(1,2)$. Primer OK ile ilişkili dört genetik hastalık vardır. Bunlar; Mc Cune-Albright's sendromu (fibrodysplasia ossificans progressiva), Albright'ın herediter osteodistrofisi, progresif osseoz heteroplazi ve Gardner sendromudur (3). Genetik sendromlarla ilişkili olmayan primer OK nedenleri de dört alt gruba ayrılır. Bunlar; yüzün multipl milier osteoma kutis (YMMOK)'i, izole osteoma, yaygın osteoma ve konjenital plak benzeri osteoma kutistir (1).

Kazanılmış bir durum olan YMMOK, yüz derisi içinde multipl, küçük, primer osteomaların varlığı ile karakterizedir. Genellikle çok sayıda, sert, deri renginde, papül ve nodüllerdir (3). Histopatolojik olarak dermiste, lameller tarzda matür kemik yapıları, perivasküler inflamasyonla çevrelenmiş kalsifiye trabeküler kemik adacıkları görülür. Primer OK, gerçek bir hamartomatöz oluşum olarak kabul edilmektedir (2). Kutanöz ossifikasyonun sebebi tam olarak bilinmemekle birlikte, kronik inflamasyon, östrojen etkisi ve 


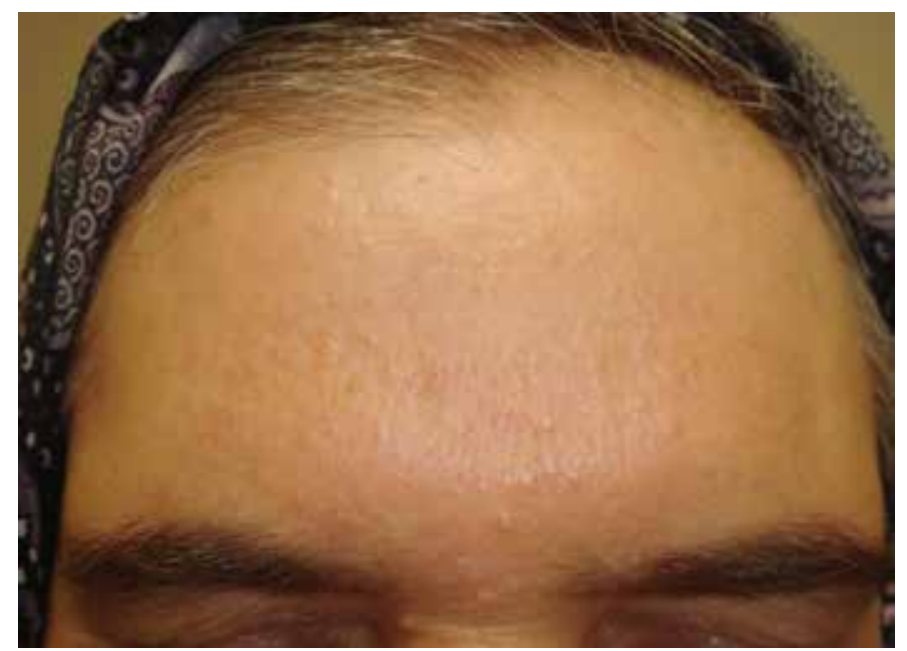

\section{Resim 1. Alında deri renginde papüler lezyonlar}

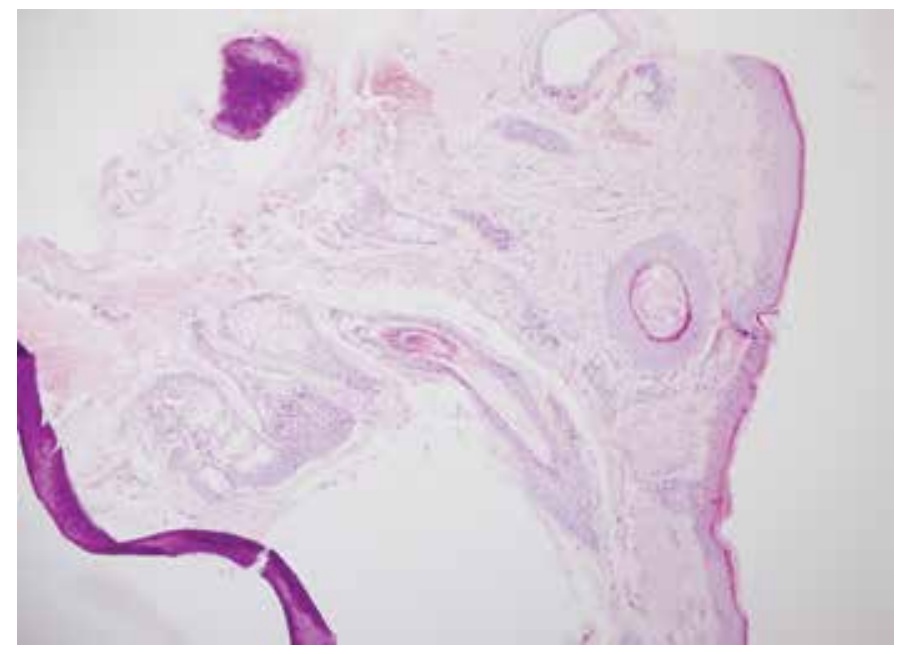

Resim 2. Dermiste, santralinde dejenerasyon ve kalsifikasyon bulunan osteoid formasyonu (x40, HE)

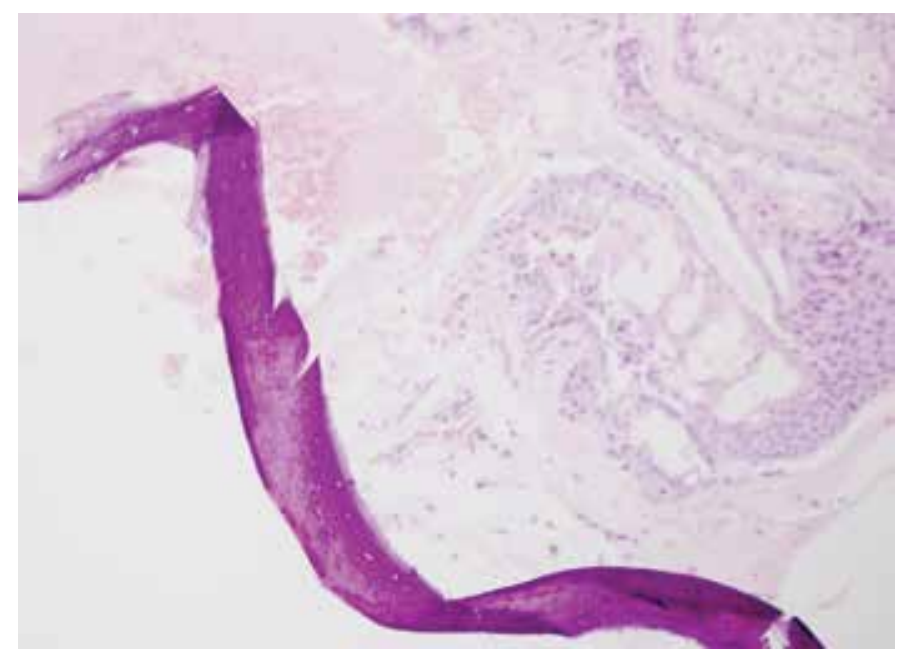

Resim 3. (x200, HE) primitif mezenkimal hücrelerin ektopik lokalizasyonunun kemik oluşumunda rol oynadığı ileri sürülmüştür (4).

\section{Olgu}

Elli altı yaşında kadın hasta, alında ve yüzde dört yıldan beri devam eden, derirenginde, çok sayıda küçükkabarıklıkşikayeti ile polikliniğimize başvurdu. Dermatolojik muayenesinde, alında ve daha az olarak her iki maksiler bölgelerde, çok sayıda, 1-5 mm çaplı, sert, deri renginde papülonodüler lezyonlar görüldü (Resim 1). Hastanın lezyonlarında hafif kaşıntı dışında subjektif şikayeti yoktu. Lezyon yerlerinde daha önceden geçirilmiş akne veya başka bir inflamatuar hastalık öyküsü mevcut değildi. Hikayesinden hipertansiyonu nedeniyle atenolol $50 \mathrm{mg} / \mathrm{gün}$ ve diz ağrıları için ağrı kesici ilaçlar kullandığı öğrenildi. Yapılan laboratuvar tetkiklerinde, açlık serum kalsiyum, magnezyum, fosfor, alkalen fozfataz düzeyleri, tiroitfonksiyonları ve kemik dansitometrisi normal bulundu. Parathormon $87 \mathrm{pg} / \mathrm{mL}$ (Normal: 11-67 pg/mL) olan hastanın vitamin D3 seviyesi $8.6 \mu \mathrm{g} / \mathrm{L}$ (Normal: 20-120 $\mu \mathrm{g} / \mathrm{L}$ ) olarak bulundu. Direkt kafa grafisinde patoloji saptanmayan hastanın diz ağrıları nedeniyle yapılan iki yönlü diz grafisinde gonartroz mevcuttu. Lezyonlardan alınan cilt biyopsisinde, dermiste, santralinde dejenerasyon ve kalsifikasyon bulunan osteoid formasyonu görüldü (Resim 2,3).

\section{Tartışma}

Osteoma kutis (OK), literatürde yalnızca olgu sunumları olarak rastlanan, iyi huylu, nadir görülen bir bozukluktur. Tüm kutanöz osteomaların yaklaşık \%85'i cilt tümörleri, inflamatuar hastalıklar, skarlar ve venöz staza sekonder olarak ortaya çıkar. Deri tümörlerinden bazal hücreli karsinoma, pilomatriksoma, hemanjiomalar ve nevüsler, inflamatuar hastalıklardan ise akne, dermatomiyozit ve skleroderma OK ile en sık birliktelik gösteren nedenlerdir (5). Primer OK'lar tüm kutanöz ossifikasyonların \% $15^{\prime}$ inden sorumludur ve herhangi bir neden olmadan ortaya çıkarlar (1). Hastamızda lezyonların yerinde geçirilmiş akne, deri tümörü, travma, enfeksiyon veya skar öyküsü yoktu. İnflamatuar hastalığı olmayan olgunun hafif parathormon yüksekliği mevcuttu. Serum kalsiyum ve fosfor seviyeleri normal sınırlarda olan hastanın hafif düzeydeki parathormon yüksekliği, $D$ vitamini eksikliğinin sonucu olarak kabul edildi. Sekonder OK nedenlerinin olmaması ile hastamızın osteomalarının primer OK olduğu kabul edildi.

Primer OK'ların nedeni tam olarak bilinmemektedir. Osteoblastların deriye anormal migrasyonu veya çeşitli uyaranların etkisi ile fibroblastların osteoblastik hücrelere metaplazisi sonucu oluştuğu yönünde hipotezler ileri sürülmüştür (4).

Primer OK tiplerinden biri olan YMMOK'ler, yüzde, deri renginde, beyaz veya mavimsi renkte, sert, küçük papüllerle karakterize, kutanöz ossifikasyon odaklarıdır. Genellikle orta yaşta ve kadınlarda daha sık görülür. Hastalığın etiyolojisi çok iyi anlaşılamamıştır. Bizim olgumuzla birlikte bugüne kadar bildirilmiş olan 53 olgunun yalnızca dokuzu erkek,

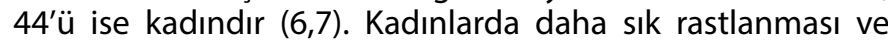
altı kadın hastada östrojen tedavisinden sonra bildirilmesi nedeniyle hormonal etkiler suçlanmış, fakat lezyonlarda östrojen reseptör-a'nın ekprese edilmediği gösterilmiştir. 
Osteomaların ortaya çıkmasında GNAS genindeki (encoding the G-protein a-stimulatory subunit) mutasyonların rol oynayabileceği düşünülmüş, fakat yapılan çalışmada bu görüşü destekleyen kanıt elde edilememiştir $(4,6)$. Myllyla ve ark., (6) 1928-2009 yılları arasında bildirilen 51 hastayı taramış ve başlangıç yaş ortalamasının 47 olduğunu bildirmişlerdir. Literatürde bu derlemeden sonra 45 yaşında bir kadın hasta bildirimi daha yapılmıştır (7). Bizim olgumuzun da şikayetleri 52 yaşında başlamıştı ve önceki olguların başlangıç yaş ortalaması ile benzerdi.

Ayırıcı tanıda akne, kalsinozis kutis, kıkırdak tümörü, yabancı cisim reaksiyonu, gut tofüsü, metastatik lezyon, pilomatriksoma, romatoid nodül, siringoma akla gelmelidir. Tedavide adapalen jel, topikal tretinoin, etidronat sodyum, cerrahi eksizyon, iğne ile mikroinsizyon ve içeriğin ekstirpasyonu, CO2 lazer, Erbium-YAG lazer ve dermabrazyon ile iyi sonuçlar bildirilmiştir $(1,8,9)$. Topikal tretinoin ile etkinin, lezyonların transepidermal eliminasyonu ile olabileceği gibi, fibroblastların normal diferansiyasyonuna yardım ederek de olabileceği düşünülmektedir (9). Biz, hastamıza topikal tretinoin \%0.05 krem başladık. Şehir dışında yaşayan hastanın takiplere gelememesi nedeniyle sonuçları değerlendirilemedi.
Çalışmamızda, nadir görülen bir hastalık olması nedeniyle YMMOK olan olgumuzun sunulması uygun görüldü.

\section{Kaynaklar}

1. Fazeli $\mathrm{P}$, Harvell J, Jacobs MB. Osteoma cutis (cutaneous ossification). West $J$ Med 1999;171:243-5.

2. Tutar E, Altınok G. Primer osteoma kutis. Ankara Patoloji Bülteni 1998;15:29-30.

3. Fairley JA. Calsifying and ossifying Disorders of the skin.In: Bolognia JL, Rapini PR, ed. Dermatology. Second edition. St Louis: Mosby; 2008. sayfa 653-60.

4. Thielen AM1, Stucki L, Braun RP, et al. Multiple cutaneous osteomas of the face associated with chronic inflammatory acne. J Eur Acad Dermatol Venereol 2006;20:321-6.

5. Ntuen EC, Guzman-Sanchez DA, McMichael AJ. Osteoma cutis as a sequela to facial acne: A case report. Cutis 2010;86:100-2.

6. Myllylä RM1, Haapasaari KM, Palatsi R, et al. Multiple miliary osteoma cutis is a distinct disease entity: four case reports and review of the literature. $\mathrm{Br} J$ Dermatol 2011;164:544-52.

7. Bouraoui S, Mlika M, Kort R, et al. Miliary osteoma cutis of face. J Dermatol Case Rep 2011;5:77-81.

8. Baskan EB, Turan $\mathrm{H}$, Tunali $\mathrm{S}$, et al. Miliary osteoma cutis of the face: Treatment with the needle microincision-extirpation method. J Dermatolog Treat 2007;18:252- 4.

9. Cohen $A D$, Chetov $T$, Cagnano E, et al. Treatment of multiple miliary osteoma cutis of the face with local application of tretinoin (all-trans-retinoic acid): a case report and review of the literature. J Dermatol Treat 2001;12:171- 3. 